\title{
Cesarean Section and Its Correlates Among Early Child Bearing Women in Nepal
}

\begin{abstract}
Background: Cesarean section (CS) is an important indicator of accessibility to emergency obstetric care. In Nepal there is a high rate of early marriage leading to increase in teen age pregnancy however, the factors associated with CS among early child bearing women remains unreported. Hence, the objective of this study is to examine the factors associated with CS among early child bearing women.
\end{abstract}

Methods: We used the 2016 National Demographic and Health Survey (NDHS) data obtained from DHS department of USAID for this study. Bivariable analysis was done using chi square test. We used logistic regression model to identify the factors associated with CS among early child bearing women.

Results: Out of 4006 women of reproductive age group from 1996 to 2016, more than $50 \%$ had early pregnancy. The population-based cesarean section (CS) rate was about $10 \%$ [95\% confidence interval: (8.9-11.6)]. Our logistic regression model showed that women with early child bearing had $32 \%$ (p-value $<0.05,95 \%$ confidence interval: $0.50-0.94$ ) less chance of having CS than women of age group 19-29 years. It was also evident that poorest women of same age group had $66 \%$ less likelihood of having CS than the richest (p-value: $<0.05,95 \%$ confidence interval: 0.29-0.99). Similarly, women from province-1, province-3 and province-4, having complete four antenatal check-ups and delivering in a private institution were associated with CS among early child bearers.

Conclusion: The odds of having CS decreased by $66 \%$ among women with early pregnancy than their counterparts after adjusting for all other covariates. This suggests that the early pregnancy might not be the risk factor for having a CS. However, we also found that this relationship might have been confounded by the interaction between wealth index and age groups as there was a huge disparity in CS rate among poorest and wealthiest women who had early child bearing. Thus, Nepal government should focus more on providing adequate accessibility to CS services throughout the population so that every woman could utilize the services in need.

Keywords: cesarean section, adolescent, early pregnancy, Nepal
Volume 10 Issue 4 - 202I

\author{
Aliza K C Bhandari,' Ashmita Adhikari, ${ }^{2}$ Mijjal \\ Shrestha, ${ }^{3}$ Mahbubur Rahman' \\ 'St. Luke's International University Graduate School of Public \\ Health, Tokyo, Japan \\ ${ }^{2}$ Mental Health Nursing Department, MM College of Nursing \\ (Maharishi Markandeshwar Deemed to be University), India \\ ${ }^{3}$ Faculty of Medicine, University of Dhaka, Bangladesh
}

Correspondence: Aliza K C Bhandari, St. Luke's Internationa University Graduate School of Public Health, Tokyo, Japan, Tel +8I-09065654748, ORCID 0000-0003-4830-6255, Email I8mp204@sicn.ac.jp

Received: June 25, 202I | Published: July 28, 2021
List of abbreviations: CS, cesarean section; NDHS, national demographic and health survey; $\mathrm{MCH}$, maternal and child health; UNICEF, united nations international children's emergency fund; USAID, united states agency for international development; WHO, world health organization; BMI, body mass index; ANC, antenatal care; MMR, maternal mortality rate; FHD, family health division; NAHDS, national adolescent health development strategy; GDP, gross domestic product; aOR, adjusted odds ratio; OR, odds ratio; cOR, crude odds ratio; $\mathrm{CI}$, confidence interval

\section{Introduction}

In today's world of independency with rapid improvement in health-quality, health-consciousness and awareness, it is dejected to note that very $5^{\text {th }}$ child is born by adolescent mothers $(<19$ years) and around eighty percentages of such early pregnancies occur in third-world countries as per the data provided by the United Nations International Children's Emergency Fund (UNICEF). ${ }^{1}$ Meanwhile, cesarean section (CS) is a surgical procedure conducted to deliver the babies by performing an incision on the mother's abdomen in order to reduce complications that may arise in the course of vaginal delivery and improve the health outcomes in both the mother and neonate. However, rate of CS has continued to rise dramatically in past 30 years. $^{2}$
There has been an upsurge in the rate of CS all over the world, data from 2016 showed that currently $18.6 \%$ births occur by CS, which is far greater than the optimum rate mentioned by WHO. The rate of CS is rising by $4.4 \%$ every year with highest being in Asia and lowest in North-America. ${ }^{3}$ Similarly, early pregnancies are also considered as a universal burden covering all countries irrespective of their economic status. ${ }^{4}$ It has been estimated that around sixteen million girls between the age of 15-19 years give birth each year globally and babies delivered from theses teen-age mothers occupies $11 \%$ of total birth worldwide. It is staggering to note that highest numbers (around 95,153) of such early pregnancies occurs in Eastern-Asia. ${ }^{5}$ Furthermore, ninety-five percentages of such birth happen to be from developing countries like Nepal. ${ }^{6}$

WHO statistics of 2014 shows that among the cause of mortality of young mothers, complications during pregnancy and delivery is the second leading factor which is highly associated with unfavorable perinatal and obstetric outcomes. ${ }^{7,8}$ Moreover, finding has represented that early pregnancies are at risk of CS nearly by $80 \%$ in comparison to older women due to reasons like biological immaturity, fetal distress, poor nutritional status, disproportion between fetus and maternal pelvis size, failure of induction and oxytocin augmentation. ${ }^{9-11}$ Sadly, early pregnancies among such young population are not a product of voluntarily choice and decision but lack of access to proper education and existing stereotype and prejudice in the communities. ${ }^{12}$ 
Speaking about Nepal, it is already fighting burden of Maternal Mortality Rate (MMR) of 281 deaths per 100,000 live births which is highest in comparison to other South-Asian countries and home delivery in unhygienic environment is another load in its back. Multi-parity, teen-age pregnancy, less or no antenatal visits being some of the basic key indicators of the vaginal delivery at home. ${ }^{13,14}$ In the study conducted in Nepal, finding has shown that nearly $2 / 3^{\text {rd }}$ of females were married before the age of 19 years in the year $2017 / 18 .^{15,16}$ Furthermore, this trend was mostly prevalent in families from lower economical groups. On the other hand, it has also been found that women having higher level of educational status have higher preference for CS. ${ }^{17-19}$ Thus, attitude and practice of Nepalese society towards child marriage, restriction of individualism and burden of imposed conclusion among girls are the root cause of the soaring rate of early pregnancies in Nepal. Government of Nepal is working vigorously in solving these issues and reducing the burden of early motherhood among adolescents. Family Health Division (FHD) has developed National Adolescent Health Development Strategy (NAHDS) in order to increase the availability with easy access of information along with counseling services for adolescents about their health. Government is playing crucial role in collaboration with various Non-Government Organization (NGO) and different medias to sensitize its population in the topics of child marriage and its complications, women empowerment and decision-making, maternal health and many more.

However, which mode of delivery is more sound and safer for adolescent pregnancy, planned vaginal or planned CS? Well, this is the new milestone and field of many clinical researches as well as the controversies too. ${ }^{20}$ In light of these growing concerns, our objective was to find the association between adolescent pregnancy and CS and identifying factors contributing to prevalence of CS among adolescent mothers in Nepal.

\section{Materials \& methods}

National Demographic and Health Survey (NDHS) data collected in the year 2016 in Nepal was used for this study. Total of 4006 women of reproductive age group who responded to the survey question indicating the method of their last birth were included and we excluded those with a missing record for our outcome variable (CS) which is defined as delivery by cesarean section and is obtained as a binary response of "Yes" or "No" in the DHS. We conducted bivariable analysis using the chi-square test and two multivariable logistic regression analysis (one to identify factors associated with CS and other factors associated with CS among early child bearing women) adjusted for all possible covariates under analysis and $p<0.05$ was used to indicate statistical significance in our models. Since this is a survey data we used "svy" command with sample weight as indicated by DHS to account for the clustering effect of the data.

\section{Ethical consideration}

We obtained permission to conduct our study using NDHS data from DHS after they reviewed our proposal on May 2019. Nepal Research Council and ICF Macro Institutional Review Board in Calverton, Maryland, USA provided ethical clearance to DHS to conduct this survey and provide access to researchers or institutions willing to use DHS survey datasets for their study. Hence, informed consent directly from participants was not a part of the present study.

\section{Results}

The sociodemographic distribution of the participants is shown in Table 1 . Nearly $37 \%$ of participants were $<18$ years (early child bearing) when they first gave birth. More than $50 \%$ of the participants had secondary or higher level of education and considerable proportion of women delivered average sized baby $(\sim 67 \%)$. Overall, nearly $6 \%$ [95\% CI: 4.4-7.6, p<0.001] of women with early child bearing had CS however, this rate was around twice among women of age group (19-29) years. Rate of CS was twice in women residing at urban areas than rural areas [12.9\% (95\% CI: $10.9-15.1, \mathrm{p}<0.001)]$. Similarly, non-government sectors are having significantly higher CS [26.3 (95\% CI: $21.8-31.4)]$ than the government sectors [12.9 (95\% CI: $11.0-15.0)$ ] (Table 1).

Table I Sociodemographic distribution of women of all reproductive age group

\begin{tabular}{|c|c|c|c|}
\hline & \multirow{2}{*}{ Overall proportion } & \multicolumn{2}{|l|}{ Proportion of CS (Cl) } \\
\hline & & Population-based CS $(\mathrm{N}=4006)$ & Institutional-based CS $(\mathrm{N}=2445)$ \\
\hline \multicolumn{4}{|l|}{ Age at first birth } \\
\hline $\begin{array}{l}\leq 18 \\
18\end{array}$ & 36.94 & $5.8(4.4-7.6)$ & $10.8(8.3-14.0)$ \\
\hline $19-29$ & 61.71 & I2.I $(10.4-14.0)$ & $18.3(15.9-20.9)$ \\
\hline$\geq 30$ & 1.35 & $37.9(24.4-53.6)$ & $45.2(29.4-62.1)$ \\
\hline$p$-value & & $<0.001$ & $<0.001$ \\
\hline \multicolumn{4}{|l|}{ Education } \\
\hline No education & 30.73 & $4.8(3.5-6.7)$ & $12.1(9.0-16.1)$ \\
\hline Primary or less & 19.05 & $6.1(4.3-8.5)$ & $11.3(8.2-15.4)$ \\
\hline Secondary or more & 50.22 & $15.2(13.2-17.4)$ & $19.2(16.7-21.8)$ \\
\hline$p$-value & & $<0.001$ & $<0.001$ \\
\hline \multicolumn{4}{|l|}{ Residence } \\
\hline Urban & 58.36 & $12.9(10.9-15.1)$ & $17.9(15.4-20.6)$ \\
\hline Rural & 41.64 & $6.7(5.3-8.6)$ & I3.7 (II.I - 16.9) \\
\hline$p$-value & & $<0.001$ & $<0.05$ \\
\hline
\end{tabular}


Table Continued...

\begin{tabular}{|c|c|c|c|}
\hline & \multirow{2}{*}{ Overall proportion } & \multicolumn{2}{|l|}{ Proportion of CS (Cl) } \\
\hline & & Population-based CS $(\mathrm{N}=4006)$ & Institutional-based CS $(\mathrm{N}=2445)$ \\
\hline \multicolumn{4}{|l|}{ Religion } \\
\hline Hindu & 87.04 & $10.1(8.7-1 \mathrm{I} .6)$ & $16.2(14.2-18.4)$ \\
\hline Non-Hindus & 12.96 & $10.6(7.4-15.0)$ & $17.6(12.6-24.1)$ \\
\hline p-value & & $>0.05$ & $>0.05$ \\
\hline \multicolumn{4}{|l|}{ Birth order } \\
\hline First & 37.54 & I5.I (I2.7- I7.9) & $18.7(15.8-22.1)$ \\
\hline Second or more & 62.46 & $7.2(6.0-8.6)$ & $14.2(11.9-16.8)$ \\
\hline p-value & & $<0.001$ & $<0.05$ \\
\hline \multicolumn{4}{|l|}{ Wealth index } \\
\hline Poorest & 25.54 & $2.9(1.9-4.4)$ & $7.4(4.8-1 \mathrm{I} .2)$ \\
\hline Poorer & 21.37 & $4.7(3.3-6.7)$ & $9.2(6.6-12.9)$ \\
\hline Middle & 20.52 & $7.8(5.7-10.8)$ & $12.6(9.2-17.0)$ \\
\hline Richer & 19.25 & $10.1(7.9-12.8)$ & $14.0(10.9-17.9)$ \\
\hline Richest & 13.33 & $29.7(25.1-34.8)$ & $32.4(6.6-12.9)$ \\
\hline$p$-value & & $<0.001$ & $<0.001$ \\
\hline \multicolumn{4}{|l|}{ Size of child } \\
\hline Large (>3500 gm) & 15.76 & $14.3(11.1-18.4)$ & $21.4(17.1-26.4)$ \\
\hline Average $(2500-3500 \mathrm{gm})$ & 66.93 & $9.1(7.9-10.5)$ & $15.0(13.1-17.1)$ \\
\hline Small (<2500 gm) & 17.31 & $10.4(7.9-13.5)$ & $16.8(\mid 2.9-21.6)$ \\
\hline p-value & & $<0.01$ & $<0.05$ \\
\hline \multicolumn{4}{|l|}{ Place of delivery } \\
\hline Government sector & 37.97 & $12.9(11.0-15.0)$ & $12.9(\mid 1.0-15.0)$ \\
\hline Non-government sector & 62.03 & $26.3(21.8-31.4)$ & $26.3(21.8-31.4)$ \\
\hline$p$-value & & $<0.001$ & $<0.001$ \\
\hline \multicolumn{4}{|l|}{ ANC visits } \\
\hline$<4$ visits & 30.23 & $4.3(3.0-6.1)$ & $12.0(8.6-16.5)$ \\
\hline$\geq 4$ visits & 69.77 & $\mid 2.8(|1.2-| 4.5)$ & $17.4(15.3-19.8)$ \\
\hline$p$-value & & $<0.001$ & $<0.05$ \\
\hline \multicolumn{4}{|l|}{ Province } \\
\hline Province I & 14.35 & $13.7(10.5-17.6)$ & $20.5(16.1-25.8)$ \\
\hline Province 2 & 18.95 & $5.6(3.8-8.1)$ & $11.7(8.2-16.5)$ \\
\hline Province 3 & 10.83 & I8.4 (I3.7- 24.I) & $24.9(19.2-31.7)$ \\
\hline Province 4 & 10.88 & $17.7(\mid 3.7-22.5)$ & $25.1(20.1-31.0)$ \\
\hline Province 5 & 16.25 & $7.2(5.3-9.8)$ & II.2(8.3- 14.9) \\
\hline Province 6 & 15.03 & $2.8(1.5-4.6)$ & $6.3(3.5-11.2)$ \\
\hline Province 7 & 13.7 & $3.9(2.4-6.0)$ & $5.5(3.5-8.5)$ \\
\hline$p$-value & & $<0.001$ & $<0.001$ \\
\hline
\end{tabular}

$p$-value obtained from chi-square test

$\mathrm{CS}=$ cesarean section

$\mathrm{Cl}=95 \%$ confidence interval

$\mathrm{ANC}=$ Antenatal care

Citation: Bhandari AKC, Adhikari A, Shrestha M, et al. Cesarean Section and Its Correlates Among Early Child Bearing Women in Nepal. MOJ Women's Health. 2021;10(4):77-83. DOI: 10.15406/mojwh.2021.10.00293 
Multivariable logistic regression analysis showed that several sociodemographic factors like age at first birth, education, province, wealth index, child size at birth and number of ANC visits were significantly associated with cesarean section. The likelihood of CS decreased by $32 \%$ [aOR: $0.68,95 \%$ CI $(0.50-0.94), \mathrm{p}<0.05]$ among early child bearing women than women of age group 19-29 years. Moreover, women with poor economic status were $76 \%$ less likely to have $\mathrm{CS}$ than those with higher economic status [aOR: $0.24,95 \% \mathrm{CI}$ $(0.17-0.33), \mathrm{p}<0.001]$ (Table 2).

Table 2 Bivariable and multivariable logistic regression analysis for the association between population-based cesarean section and sociodemographic factors

\begin{tabular}{|c|c|c|}
\hline \multicolumn{3}{|c|}{ Odds ratio (OR) } \\
\hline & Crude OR (Cl) & Adjusted OR (Cl) \\
\hline \multicolumn{3}{|l|}{ Age at first birth } \\
\hline $19-29$ & I & I \\
\hline$\leq 18$ & $0.45(0.32-0.62)^{* * *}$ & $0.68(0.50-0.94)^{*}$ \\
\hline$\geq 30$ & $4.44(2.35-8.38)^{* * *}$ & $3.89(2.00-7.56)^{* * *}$ \\
\hline \multicolumn{3}{|l|}{ Education } \\
\hline No education & I & I \\
\hline Primary or less & $1.28(0.80-2.04)$ & $1.07(0.68-1.70)$ \\
\hline Secondary and above & $3.53(2.38-5.25)^{* * *}$ & $1.63(1.11-2.39)^{*}$ \\
\hline \multicolumn{3}{|l|}{ Province } \\
\hline Province 7 & I & I \\
\hline Province I & $3.96(2.26-6.92)^{* * *}$ & $3.01(1.76-5.14)^{* * * *}$ \\
\hline Province 2 & $1.47(0.79-2.74)$ & $1.50(0.81-2.78)$ \\
\hline Province 3 & $5.62(3.13-10.08)^{* * *}$ & $3.24(1.87-5.61)^{* * *}$ \\
\hline Province 4 & $5.35(3.06-9.37)^{* * *}$ & $4.01(2.37-6.80)^{* * *}$ \\
\hline Province 5 & $1.94(1.09-3.47)^{*}$ & $1.36(0.78-2.35)$ \\
\hline Province 6 & $0.68(0.33-1.42)$ & $1.06(0.52-2.16)$ \\
\hline \multicolumn{3}{|l|}{ Wealth index } \\
\hline Rich & I & I \\
\hline Poor & $0.17(0.12-0.24)^{* * *}$ & $0.24(0.17-0.33)^{* * * *}$ \\
\hline Average & $0.37(0.25-0.55)^{* * *}$ & $0.55(0.37-0.81)^{* *}$ \\
\hline
\end{tabular}

\section{ANC visits}

$\begin{array}{lll}<4 \text { visits } & \mathrm{I} & \mathrm{I} \\ \geq 4 \text { visits } & 3.24(2.2 \mathrm{I}-4.74)^{* * * *} & \mathrm{I} .75(\mathrm{I} .2 \mathrm{I}-2.53)^{* *} \\ \text { Child size } & \mathrm{I} & \mathrm{I} \\ \text { Average } & \mathrm{I} .67(\mathrm{I} .22-2.28)^{* * *} & \mathrm{I} .63(\mathrm{I} .23-2.16)^{* *} \\ \text { Large } & \mathrm{I} .16(0.84-1.59) & \mathrm{I} .44(\mathrm{I} .05-\mathrm{I} .98)^{*}\end{array}$

Number of participants included in the multivariable logistic regression model, $N=3997$ (nine women had missing records for child size)

$\mathrm{OR}=$ Odds ratio

Crude odds ratio was obtained from bivariable logistic regression analysis

Adjusted odds ratio was obtained from multivariable logistic regression analysis which was adjusted for all covariates under analysis

ANC $=$ Antenatal care

$\mathrm{Cl}=95 \%$ confidence interval

$*=P<0.05, * *=P<0.01, * * *=P<0.001$ 
The separate multivariable logistic regression analysis performed to find the factors associated with CS among early child bearing women showed that province, wealth index, number of ANC visits and place of delivery were the major factors affecting the rate of CS among this age group. The likelihood of CS was four to six-fold higher in province 1, 3 and 4 than province 7. Similarly, poor women of this age group had $46 \%$ less likelihood of having CS than that of rich women of same age group [aOR: $0.54,95 \%$ CI $(0.29-0.99)$, $\mathrm{p}<0.05]$. We depicted the relationship between CS and various wealth quintiles among early child bearing women in "supplementary file 1". Meanwhile, women having more than four ANC visits were also having higher CS rate than those who had less than four ANC visits. Women with early child bearing were twice as likely to have CS in non-governmental sectors than the government sectors [aOR: 2.38, $95 \%$ CI $(1.35-4.21), \mathrm{p}<0.01]$ (Table 3 ).

Table 3 Bivariable and multivariable logistic regression analysis to identify factors associated with CS among early child bearing women ( $\leq 18$ years)

\begin{tabular}{|c|c|c|c|}
\hline & $\begin{array}{l}\text { Proportion of CS } \\
(\mathrm{Cl}), \mathrm{N}=1480\end{array}$ & cOR (Cl) & aOR (Cl) \\
\hline \multicolumn{4}{|l|}{ Education } \\
\hline No education & $4.4(2.7-7.0)$ & 1 & 1 \\
\hline Primary or less & $5.6(3.4-8.9)$ & $1.30(0.66-2.55)$ & $0.65(0.32-1.33)$ \\
\hline Secondary and above & $7.3(5.0-10.6)$ & $1.74(0.91-3.33)$ & $0.62(0.33-1.18)$ \\
\hline \multicolumn{4}{|l|}{ Province } \\
\hline Province 7 & $1.8(0.6-4.8)$ & 1 & 1 \\
\hline Province I & $8.1(4.6-13.8)$ & $4.88(1.49-15.99)^{* *}$ & $4.59(1.34-15.78)^{*}$ \\
\hline Province 2 & $4.8(2.7-8.3)$ & $2.79(0.85-9.09)$ & $2.74(0.8 I-9.26)$ \\
\hline Province 3 & $9.7(4.5-19.6)$ & $5.93(1.59-22.06)^{* *}$ & $6.10(1.60-23.22)^{*}$ \\
\hline Province 4 & $11.8(7.0-19.3)$ & $7.42(2.29-24.06)^{* *}$ & $6.75(1.89-24.08)^{* *}$ \\
\hline Province 5 & $3.9(2.0-7.4)$ & $2.24(0.65-7.69)$ & $2.13(0.62-7.27)$ \\
\hline Province 6 & $2.6(0.9-7.4)$ & $1.49(0.33-6.66)$ & $2.50(0.52-12.02)$ \\
\hline \multicolumn{4}{|l|}{ Wealth index } \\
\hline Rich & $10.4(7.2-14.7)$ & 1 & 1 \\
\hline Poor & $3.2(2.0-5.0)$ & $0.28(0.16-0.49)^{* * * *}$ & $0.54(0.29-0.99)^{*}$ \\
\hline Average & $5.7(3.0-10.7)$ & $0.52(0.23-1.19)$ & $0.62(0.28-1.37)$ \\
\hline \multicolumn{4}{|l|}{ ANC visits } \\
\hline$<4$ visits & $2.6(1.5-4.5)$ & 1 & 1 \\
\hline$\geq 4$ visits & $7.8(5.9-10.2)$ & $3.18(1.77-5.70)^{* * * *}$ & $1.02(1.48-3.53)^{*}$ \\
\hline \multicolumn{4}{|l|}{ Child size } \\
\hline Average & $5.6(4.0-7.7)$ & 1 & 1 \\
\hline Large & $7.2(4.3-11.8)$ & I.3I (0.7I - 2.44) & $1.42(0.73-2.79)$ \\
\hline Small & $5.5(3.1-9.5)$ & $0.99(0.5 \mathrm{I}-\mathrm{I} .90)$ & $1.10(0.57-2.12)$ \\
\hline \multicolumn{4}{|l|}{ Place of delivery } \\
\hline Government & $8.7(6.2-12.2)$ & 1 & 1 \\
\hline Private & $16.6(11.6-23.2)$ & $2.08(1.21-3.56)^{* * *}$ & $2.38(1.35-4.2 \mathrm{I})^{* *}$ \\
\hline
\end{tabular}

Number of participants included in the multivariable logistic regression model, $\mathrm{N}=809$

$\mathrm{CS}=$ cesarean section

ANC $=$ Antenatal care

COR $=$ Crude odds ratio obtained from bivariable logistic regression analysis

$\mathrm{aOR}=$ Adjusted odds ratio obtained from multivariable logistic regression analysis which was adjusted for all covariates under analysis, $\mathrm{Cl}=95 \%$ confidence interval

$*=P<0.05, * *=P<0.01, * * *=P<0.001$

Citation: Bhandari AKC,Adhikari A, Shrestha M, et al. Cesarean Section and Its Correlates Among Early Child Bearing Women in Nepal. MOJ Women's Health. 202।;I0(4):77-83. DOI: I0.I5406/mojwh.202I.I0.00293 


\section{Discussion}

This study was conducted with the aim of finding out the factors associated with CS among early child bearers. CS is incorporated as a standard part of modern medical era and institutionalization of delivery is considered as a major pillar for the safe childbirth. ${ }^{21}$ In developing countries like Nepal, lack of awareness among general population and existing sociocultural norms are overt forces pushing the adolescents towards early marriage and centralized health care delivery system are enabling for unsafe home deliveries despite of fatal risk and complications.

This study identified advancing age as a risk factor of CS which was similar to the results from other study. ${ }^{22}$ However, lower level of CS among early pregnant mothers might be highly influenced by their health seeking patterns. Subjective components like lack of autonomy, low decision-making power, perception towards health and pregnancy, diffidence with male health care providers could be the barriers of health seeking behavior ultimately resulting in vaginal and home deliveries. ${ }^{12,14}$ In line with many studies, our results found that pregnant woman with higher educational status are found to be more gravitated towards CS. ${ }^{23,24}$ Moreover, association has been found between female education and uses of health care facilities along with the result of home deliveries occurring among woman having lower educational level and the other way around..$^{25,26}$

In the similar terms, CS rate has also been varied among the setting of stay too, these differences might be the results of economical deprivations in the rural part where peoples are mostly engaged in activities for basic survival having no access to the education and awareness regarding maternal health care and CS. The urbanization in Nepal is dominated by very few large cities with massive population concentration in Kathmandu valley creating the maldistributions of health care services and health care providers too. ${ }^{27}$ Similar results regarding health service accessibility have been shown in researches conducted at other South-Asian countries. ${ }^{28,29}$ Some studies suggests that enrollment in birth preparedness and raising awareness programs motivates the pregnant mother to visit and ask for maternal health services. $^{30}$

The negligible difference in the proportion of CS among different religions puts the light over the effectiveness of sensitization programs launched by Nepal government to break the stereotype that exist among different religions..$^{31,32}$ Likewise, the greater proportion of the CS among the primigravid mothers like that of other studies illustrates the raising consciousness among the early pregnant mothers regarding the risk associated with early pregnancy ${ }_{.3}^{33}$ Moreover, the lowest rate of CS among the poorest early child bearing women and its increasing trend as we move to higher class of wealth index is alike the past results from multiple studies. ${ }^{34}$ Having said that, the current rate of CS among the underprivileged groups are also the new achievement for the developing countries like Nepal. Similarly, increasing ANC visits represent the gradual awareness of Nepalese women regarding the risks and complications of early pregnancy. ${ }^{35,36}$ Overall, the results suggest the ongoing necessity of establishment of knowledge sharing platform like different clubs and groups among woman from all provinces to clarify the need and importance of ANC visit, maternal and reproductive health along with pregnancy and scope of CS..$^{37,38}$

\section{Conclusion}

This study revealed that early pregnancy is significantly associated with CS whether due to complication or to protect maternal and neonatal health. All in all, there is the paramount need of strong policies and programs to connects all these dots that exist in utilization of $\mathrm{MCH}$ services by young mothers.

\section{Strength \& limitation}

The findings of present study are useful in closing the gap that is prevalent among early pregnant women of different sociodemographic classes from using the existing maternal health care facilities. However, due to the small count of CS we could not perform model fitting including interaction of early pregnancy with major confounders. Similarly, due lack of information on indication of CS we were not able to analyze reasons for preferring CS. In contempt of these limitation present study stands to be mirror image for evaluation of present status of Nepal showing the outcomes of different programs commenced to end early pregnancy and availability of impartial health care services to all citizens.

\section{Declarations}

\section{Ethical approval and consent to participate}

This study analyzed data extracted from the NDHS 2016. The ethical clearance for DHS survey was obtained from Nepal Research Council and ICF Macro Institutional Review Board in Calverton, Maryland, USA. The DHS data are publicly accessible, and we obtained the permission to use it in May 2019 after DHS reviewed our proposal and we accepted the terms and conditions attached with data sharing policy. Informed consent was taken by DHS with the participants prior to this survey (25).

\section{Consent for publication}

Not applicable.

\section{Availability of data and materials}

The National Demographic and Health Survey data of Nepal can be obtained from the USAID's official website (25).

\section{Competing interests}

The authors declare no competing interests.

\section{Funding}

The authors received no specific funding for this research.

\section{Author contributions}

Conceptualization AB, MR; Methodology AB, MR; Validation $\mathrm{AB}$; Formal analysis $\mathrm{AB}$; Investigation $\mathrm{AB}$; Resources $\mathrm{AB}, \mathrm{AA}, \mathrm{MS}$; Data curation $\mathrm{AB}, \mathrm{MR}$; Writing - original draft preparation $\mathrm{AB}, \mathrm{AA}$, MS; Writing - review and editing AB, AA, MS, MR; Visualization AB; Supervision MR; Project administration AB, AA, MS. All authors have read and approved the final manuscript.

\section{Acknowledgments}

The authors much appreciate St. Luke's International University, Tokyo Japan for providing an opportunity and guidance in conducting this study and also would like to extend their gratitude towards all the individuals involved in the data collection and management process for the DHS program. A deep appreciation to all the well-wishers. The statements made herein are solely the responsibility of the author.

\section{References}

1. UNFPA - United Nations Population Fund. Adolescent pregnancy. 2020. 
2. Betrán AP, Ye J, Moller AB, et al. The increasing trend in caesarean section rates: Global, regional and national estimates: 1990-2014. PLoS One. 2016; 11(2): $\mathrm{e} 0148343$.

3. Betran AP, Torloni MR, Zhang J, et al. No Title.

4. UNICEF. Ending child marriage: Progress and prospects. New York: UNICEF. 2013

5. WHO. What is the Global Strategy? 2020.

6. WHO. Adolescent pregnancy:Factsheets. 2014.

7. Abebe AM, Fitie GW, Jember DA, et al. Teenage Pregnancy and Its Adverse Obstetric and Perinatal Outcomes at Lemlem Karl Hospital, Tigray, Ethiopia, 2018. Biomed Res Int. 2020;2020:3124847.

8. Santos NL, Costa MC, Amaral MT, Vieira GO, Bacelar EB, de Almeida AH. Gravidez na adolescência: análise de fatores de risco para baixo peso, prematuridade e cesariana [Teenage pregnancy: analysis of risk factors for low birth weight, prematurity and cesarean delivery]. Cien Saude Colet. 2014;19(3):719-726.

9. Yussif AS, Lassey A, Ganyaglo GYK, et al. The long-term effects of adolescent pregnancies in a community in Northern Ghana on subsequent pregnancies and births of the young mothers. Reprod Health. 2017;14(1):178.

10. Katz Eriksen JL, Melamed A, Clapp MA, et al. Cesarean Delivery in Adolescents. J Pediatr Adolesc Gynecol. 2016;29(5):443-447.

11. Rahman MM, Haider MR, Moinuddin M, et al. Determinants of caesarean section in Bangladesh: Cross-sectional analysis of Bangladesh demographic and health survey 2014 data. PLoS ONE. 2018;13(9): e0202879.

12. Adolescent pregnancy | UNFPA - United Nations Population Fund. 2020

13. Shrestha SK, Banu B, Khanom K, et al. Changing trends on the place of delivery: Why do Nepali women give birth at home? Reprod Health. 2012;9(1):25.

14. Shahabuddin ASM, Delvaux T, Nöstlinger C, et al. Maternal health careseeking behaviour of married adolescent girls: A prospective qualitative study in Banke District, Nepal. PLoS One. 2019;14(6): e0217968.

15. Gurung R, Målqvist M, Hong $Z$, et al. The burden of adolescent motherhood and health consequences in Nepal. BMC Pregnancy Childbirth. 2020;20(1):318.

16. Khem D, Karki B, Maiya T, et al. Child Marriage in Nepal Research Report Design and Print Horizon Creation Child Marriage in Nepal. 2012.

17. Collin SM, Marshall T, Filippi V. Caesarean section and subsequent fertility in sub-Saharan Africa. BJOG: An International Journal of Obstetrics and Gynaecology. 2006;113(3):276-83.

18. Karlström A, Engström-Olofsson R, Nystedt A, et al. Swedish caregivers' attitudes towards caesarean section on maternal request. Women and Birth. 2009;22(2):57-63.

19. Bhattarai A, Dharel D, Kumar N. The Safe Delivery Incentive Program in Nepal: towards women's empowerment. Int J Med Sci public Heal. 2016;5(10):2108-2113

20. Little MO, Lyerly AD, Mitchell LM, et al. Mode of delivery: Toward responsible inclusion of patient preferences. Obstetrics and Gynecology. 2008;112(4):913-918
21. Sarmiento A. Trends in Cesarean Section. In: Caesarean Section [Internet]. InTech. 2018.

22. Janoudi G, Kelly S, Yasseen A, et al. Factors Associated With Increased Rates of Caesarean Section in Women of Advanced Maternal Age. $J$ Obstet Gynecol Can. 2015;37(6):517-526.

23. Myer L, Mlobeli R, Cooper D, et al. Knowledge and use of emergency contraception among women in the western cape province of South Africa: a cross-sectional study. BMC Womens Health. 2007;07:14.

24. Rosenberg M, Pettifor A, Miller WC, et al. Relationship between school dropout and teen pregnancy among rural south A young women. IJE. 2015;44:928-936.

25. DHS: Nepal Demographic and Health Survey 2006. Maryland Calverton: Population Division, Ministry of Health and Population, Government of Nepal, Kathmandu, Nepal and Macro International. 2007.

26. Bhandari AKC, Dhungel B, Rahman M. Trends and correlates of cesarean section rates over two decades in Nepal. BMC Pregnancy Childbirth 2020;763:2020

27. Urbanisation and urban growth in Nepal - GSDRC. 2020

28. Anwar I, Kalim N, Koblinsky M. Quality of obstetric care in publicsector facilities and constraints to implementing emergency obstetric care services: evidence from high-and low-performing. J Heal Popul. 2009;27(2):139-155.

29. Islam F, Rahman A, Halim A, et al. Perceptions of health care providers and patients on quality of care in maternal and neonatal health in fourteen B government health-care facilities: a mixed-method study. BMC Health Serv Res. 2015;15:237.

30. Parkhurst JO, Rahman SA. Overcoming access barriers for facility-based delivery in low-income settings Insights from Bangladesh and Uganda. $J$ Heal Popul Nutr. 2006;24(4):438-445.

31. Subedi M. Caste system: theories and practices in Nepal. Himalayan $J$ Sociol Anthropol. 2010;4:134-159.

32. Langer JA, Ramos JV, Ghimire L, et al. Gender and Child behavior problems in rural $\mathrm{N}$ differential expectations and responses. Sci Rep. 2019;9(1):7662.

33. Saha L, Chowdhury SB. Study on primary cesarean section. Mymensingh Med J. 2011;20(2):292-297

34. Government of Nepal. Progress of the health sector FY 2017/28. 2020.

35. Pradhan A. Situation of antenatal care and delivery practices. Kathmandu Uni Med J. 2005;11(3):266-270.

36. Klaki CU, Inaku JU, Ekabua JE, et al. Perinatal outcome in unbooked teenage pregnancies in the university of calabar teaching hospital., calabar Nigeria. ISRN Obstet Gynecol. 2012;2012:246983.

37. Zambon A, Morgan A, Vereecken C, et al. The contribution of club participation to adolescent health: evidence from six countries. J Epidemiol Community Health. 2010;64(1):89-95.

38. WHO. Making Health Services Adolescent Friendly-Developing National Quality Standards for Ado- lescent Friendly Health Services. World Health Organization. 2012;1-56. 